Article

\title{
Investigating the Potential of Gamification to Improve Seniors' Experience and Use of Technology
}

\author{
Michael Minge ${ }^{1, *(1)}$ and Dietlind Helene Cymek ${ }^{2}$ \\ 1 Cognitive Psychology and Cognitive Ergonomics, Technische Universität Berlin, 10587 Berlin, Germany \\ 2 Work and Organisational Psychology, Technische Universität Berlin, 10587 Berlin, Germany; \\ dietlind.h.cymek@tu-berlin.de \\ * Correspondence: michael.minge@tu-berlin.de
}

Received: 31 January 2020; Accepted: 22 April 2020; Published: 2 May 2020

\begin{abstract}
A non-negligible proportion of seniors rarely uses new technology. Far too often, these rather tech unexperienced seniors struggle with new soft- or hard-ware, that do not provide easy access. As a result, some seniors avoid or completely desist to further use "these modern technologies" and consequently miss out on the benefits of digital age. Game-inspired design is supposed to be a promising way to overcome some perceived barriers of seniors by providing hedonic value during early interaction. Previous research has shown that game-inspired design is suitable to motivate seniors' use of Health-IT. To investigate its potential to facilitate the use of information and communication technology (ICT), an experimental study was conducted. The study investigated the appeal of various gamification features, which were embedded in a prototype of an ICT learning software and compared it to a non-gamified version of the software. Results indicate that the concept of gamified ICT learning software appeals to seniors in general, but that the acceptance of different gamification features is quite diverse. A clear-cut superiority of adding gamification to the software was not found. After interacting with both software versions, seniors in around equal parts preferred either the non-gamified version, the gamified version, or could not decide. Those seniors that clearly favored the gamified version were particularly fond of continuous positive feedback and receiving rewards for each task they have accomplished. Whereas the remaining seniors rather disliked the intensive endorsement through these two features and decided against the gamified version, albeit they liked many of the other game features. Our results underline the necessity of following a user-centered design approach when developing game-inspired applications, and the need for an individualized use of gamification elements to meet the needs of the heterogeneous group of senior users.
\end{abstract}

Keywords: gamification; technology; senior users; user experience; motivation

\section{Introduction}

\subsection{Game-Inspired Design}

Game playing is supposed to be a promising way to elicit emotional experiences [1], to promote meaningfulness and happiness [2-4], and to enhance engagement as well as task performance [5]. For this reason, games and game mechanics can be frequently found in our daily activities [6], including the technology we interact with. Promising application domains of game mechanics are educational software [7-9], bonus and discount systems [10], productivity and working software [11,12], social media [13,14], as well as healthcare and fitness training [15-18].

By the term 'game-inspired design', Darejeh and Salim [19] subsume the adoption of any aspects of games and game playing in the development of interactive applications and technical systems. 
Their concept of game-inspired design differentiates 'serious games' and 'gamification' as two different forms of implementation. The first form, 'serious games', provides a full and rather complex game environment that is generally designed to support meaningful purposes, such as training and education. The advantage of serious games, such as flight or surgical simulations, is that high-risk situations and actions can be explored and trained in a quiet realistic setting without the actual risk. Systematic reviews of various serious games showed that knowledge, skills, and satisfaction with learning outcomes can be improved [20]. The second form 'gamification', which is in focus of the here presented research, is defined as the use of game features and mechanics in non-game contexts [21]. Gamification elements comprise badges, leader boards, and rewards, but also mechanisms as visualization of characters, storytelling, interactivity, and problem solving [22,23].

Gamification aims at motivating users to perform a specific activity on a regular basis or to reach a certain quality standard. This is achieved by directly satisfying basic psychological needs, such as competence, relatedness, and autonomy [24,25]. According to the self-determination theory (SDT) [26], these psychological needs are the basic elements for facilitating (or undermining) intrinsic motivation and able to support personal growth and wellbeing. SDT predicts that humans are highly engaged in activities that are closely related to these needs. Tolks and colleagues have succeeded in assigning the most prominent game elements to the three basic psychological needs of the SDT - competence, relatedness, and autonomy [27]. This assignment is empirically supported by studies that found positive effects of game elements on competence [28], autonomy [29], and relatedness [30]. Beside these studies, a meta-analysis of Sailer and Homner [31] found further positive effects of gamification on cognitive, motivational, and behavioral learning outcomes. In the context of health design, gamification also improved ratings of perceived user-friendliness and acceptance of interactive training systems [32].

However, game elements are usually implemented as additional features to a system [19]. For this reason, the concept of gamification has also drawn some criticism, both from academia and from industry $[33,34]$. For example, adding gamification elements to an existing application has been described as a "customer loyalty program repackaged with a superficial gamy veneer" [34], p. 306, an "inadvertent con" and nothing more than "pointsification" [35]. Solely using conditioning processes to motivate a specific user behavior extrinsically was criticized to result in structures of hierarchy and dehumanization [36] and may even result in long-term deterioration of intrinsic motivation [37]. Furthermore, a number of reviews that investigated the effectiveness of gamified design solutions concluded that the potential of game features is limited and that their effects are overestimated in many cases $[19,38,39]$. Some experts even believe that 80 percent of gamification projects will fail $[40,41]$ because of insufficient knowledge of the intended user group and their specific needs. To avoid these side effects, gamification must be understood as a "holistic, systematic practice" [32] that needs to be carefully planned [23], context sensitive, and greatly focused on the applications' meaningfulness to the user group [37]. We argue that a thorough investigation of user needs is required for gamified applications to exploit their full potential. This can only be realized by a user-centered development process that integrates prototype testing with users early in the design process.

\subsection{Game-Inspired Design for Senior Users}

Nowadays, games play a notable role in the life of many seniors [42]. There is even a growing proportion of elderly users that engages in playing digital games called silver gamers [43]. Against this background, it can be supposed that senior users also have a certain affinity towards game-inspired design.

We believe that the use of game mechanics could be particularly valuable in the domain of seniors' technological education. Knowing how to use the internet and new information and communication technologies (ICT) is an essential skill nowadays. People who never or seldom use these technologies may experience a growing gap between them and the rest of society. In particular, those who rarely or never interacted with ICT before, struggle to understand them. They are lacking relevant prior knowledge that is often presumed by the design. Past negative experiences and difficulties with 
ICT add up and may result in a hindering form of anticipated user experience regarding unfamiliar technologies. Therefore, ICT design must help overcome fear and helplessness associated with new devices and software. Gamification can be helpful to break this cycle of negative expectations and provide knowledge step by step, enabling inexperienced senior users to benefit from the advantages of modern ICT-if they wish to.

However, game-inspired design for seniors has not received much attention in the development of common interactive technical products. By now, game-inspired design for seniors mainly focused on healthcare and therapeutic applications [44]. For instance, Gomez-Gurley et al. [45] implemented a cognitive training tool that simulated a cooking station for adults with disabilities. Another study by Gerling and Masuch [46] investigated the effects of an application with gamification elements to support social interaction in physical and cognitive therapy and found evidence for a positive short-term impact on motivation and user experience ratings. Most of the available studies acknowledge limitations, such as methodological issues and challenges with respect to the specific target group, e.g., a tendency for social desirability and the lack of prior experience with technology as well as computer games [47]. It further seems that with advancing age, older users perceive gamification as less understandable and thus can benefit less of it [48].

Altogether, far too little is known about how older adults experience gamification and whether game-inspired design can improve motivation and skills in other domains than healthcare. To answer these questions, the following user test aimed to systematically investigate how older adults perceive gamification elements in an interactive prototype of an ICT learning application ('PC-Trainer'). PC-Trainer was designed as a sandbox-type, risk-free software. To learn about the effect of adding gamification, one gamified version and another non-gamified, purely pragmatic version of PC-Trainer were developed and tested under laboratory conditions in an experimental setting. To develop empathy for the specific needs and requirements of senior users, and to be able to build a useful and user-centered PC-Trainer, comprehensive qualitative interviews and two focus groups were conducted beforehand. The semi-structured interviews explored specific user needs, ICT usage habits, common difficulties with ICT, and senior's motives to engage in all kind of games and leisure activities [42]. The results hinted at some promising possibilities to address frequent ICT problems, such as the handling of complicated operating menus and the installation of new soft- or hardware, by game mechanics. To learn how design should be inspired by games in order to appeal to seniors, attitudes towards gamification and serious games were investigated in two focus groups, [49]. Based on the knowledge gained, the two PC-Trainer software prototypes for the here presented user-test were built. Throughout the user test, quantitative data was collected to learn about older adults' attitude towards the implemented gamification elements, as well as the possible impact of these elements on the perception of interaction quality and user experience. We expected that gamification influenced some components of user experience, like positive emotions and visual aesthetics. We were also interested in the attitude towards the gamified system, system preference and opinions about the specific gamification elements implemented.

\section{Method}

\subsection{Participants}

Forty-eight participants (24 women, 24 men) completed the user test. Their ages ranged from 60 to 79 years $(M=69.67, S D=4.77)$. While 27 participants lived on their own, 19 participants lived with domestic partners, and another two in senior citizens' apartments. The educational level was well balanced: 26 participants held a university-entrance diploma ("Abitur"), 21 did not. By answering the item "I like to spend my time playing games" using a scale from 1 ("absolutely disagree") to 5 ("absolutely agree"), participants reported a medium level of overall affinity towards games $(M=2.98$; $S D=1.17)$. With regard to technology acceptance, the analysis of the technology commitment questionnaire by Neyer et al. [50] revealed that 18 participants had a medium level of openness towards 
new technology, while 14 persons reached a score in the lower third of the scale, and 16 participants were in the top third.

\subsection{Stimulus and Apparatus}

The basic idea of both PC-Trainer versions (gamified and non-gamified), was that users are given tasks which they can complete on their own without doing damage. This includes that if the solution of a task is unknown, participants can try out and explore the system functions in a risk-free environment (see Figure 1). Tasks were grouped according to two fields of application: Computer basics in the Microsoft Windows ${ }^{\circledR}$ operating system (i.e., opening a folder, minimizing a window, using a shortcut and renaming or deleting a folder) and the video-chat software Skype ${ }^{\mathrm{TM}}$ (i.e., making a call, editing global settings, adding a contact to the favorites). In case participants were unable to complete a task without support, they were instructed to click on an all-time visible help button to access a step-by-step instruction, which was written in everyday language and avoided unnecessary technical terms.

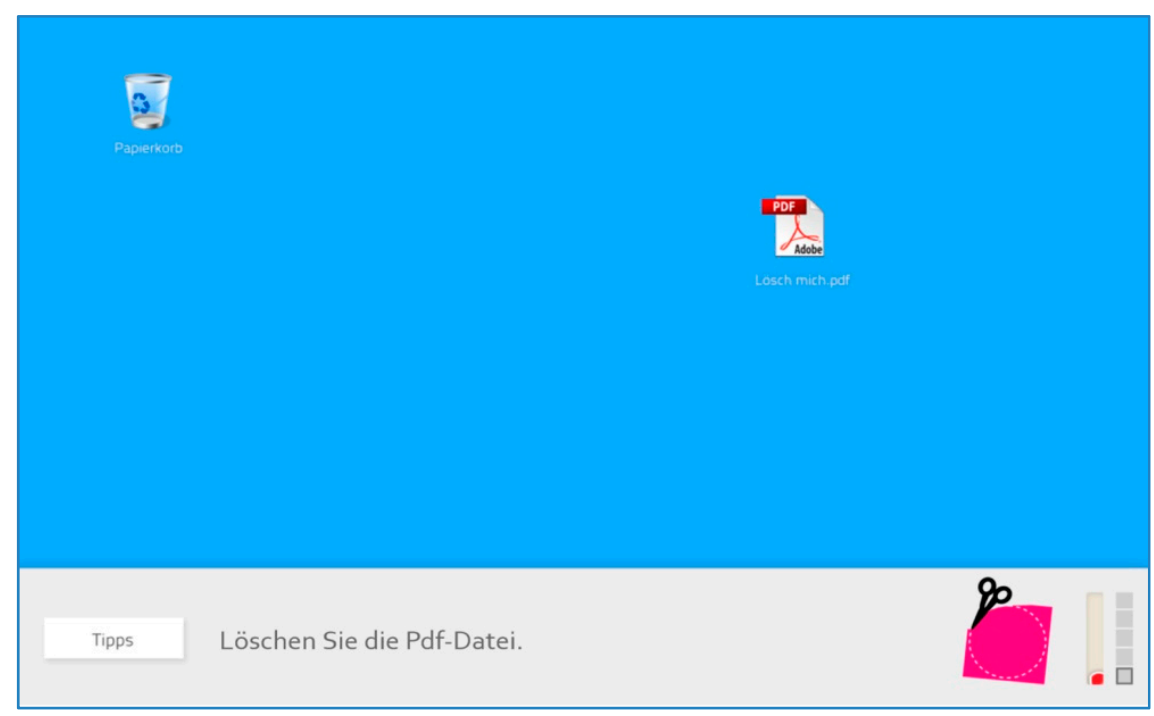

Figure 1. Screenshot of the gamified PC-Trainer used in the experiment. Participants should "delete the PDF file". The help button is located at the lower left.

PC-Trainer was implemented in two variants, one version included seven gamification elements, and one version did not. The gamification itself was designed to be rather "mild" as well as "meaningful" for the participants, in order to not induce feelings of ridiculousness or too much (time) pressure, which could be counterproductive [49]. The overall goal of the gamified application was to complete a puzzle. Puzzle pieces could be earned by accomplishing as many tasks as possible without help. The specific elements used in the gamified version are shown in Figure 2. They included:

Task difficulty (1). The PC-trainer allows users to work on tasks from different domains (i.e., Microsoft Windows ${ }^{\circledR}$ and Skype ${ }^{\mathrm{TM}}$ ) with three levels of difficulty, respectively (easy, medium, and difficult). At each level, five tasks can be solved. In the present study, all users worked on the Windows ${ }^{\circledR}$ tasks with easy and medium difficulty and on easy Skype ${ }^{\mathrm{TM}}$ tasks. It was assumed that the level of task difficulty provides a feedback on personal ability and competence. Furthermore, the categorization is associated with different levels of mental effort, therefore, participants received a higher reward for solving more challenging tasks.

Task reward (2). For each accomplished task, participants received a blue square. For more challenging tasks, the number of squares was doubled or even tripled. When a set of four blue squares was earned, the squares formed together one puzzle piece. In order to motivate self-exploration, accomplished tasks were not rewarded with a blue square when the help function was used. However, participants were always free to use the help function if it was needed. 
Speed reward (3). When solving a task rather quick, participants received a bonus, which could be redeemed in additional puzzle pieces. The speed reward was an add-on reward on purpose, to not frustrate slow-paced participants, and simultaneously encourage repeated task fulfillment until the task could be done in a moderate pace without much cognitive effort. This aimed to support better long-term memory retention.

Positive feedback (4). After completing a set of five tasks, a feedback window was displayed congratulating on new achievements, i.e., showing the number of blue squares and the amount of speed reward which were collected. In a following step, an animation illustrated how many new puzzle pieces were acquired within a set of five tasks.

Long-term objective (5). All collected puzzle pieces formed together a puzzle. When a puzzle was completed, learners received a little surprise in form of a short comedic video.

Progress (6). In the main selection window, a vertical bar was displayed that fills up as the user completed tasks without help. The progress bar served as a feedback on increasing competence.

Personal profile (7). Each user had a profile to track achievements over time. Participants had the choice to customize the design of the game by displaying either a picture of oneself or an avatar.

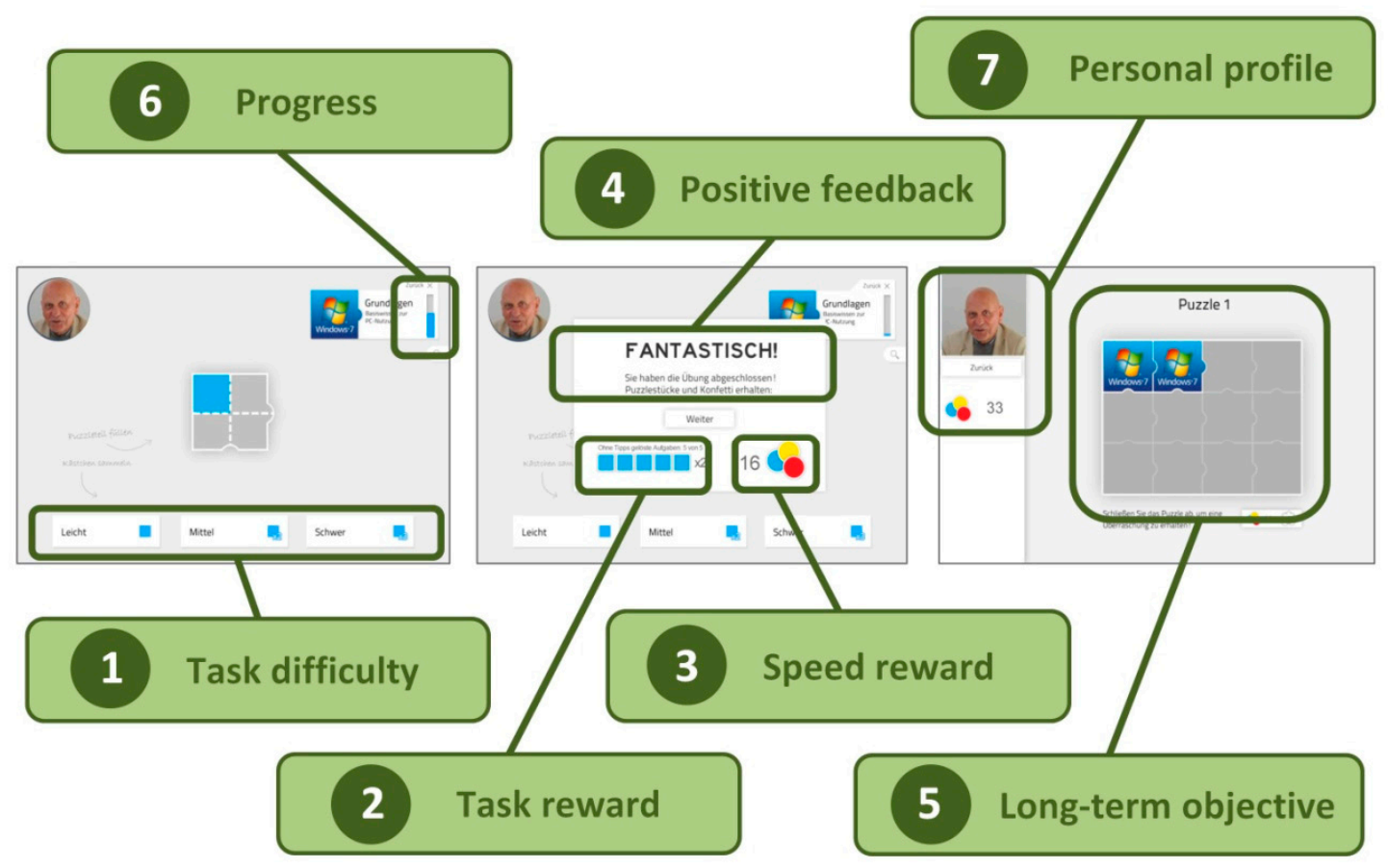

Figure 2. Screenshots and gamification elements of the gamified PC trainer application. Screenshots are showing the task selection window (left), the feedback pop-up after solving a set of five tasks displaying "Congratulation" (middle), and the personal profile depicting the puzzle (right).

The selection of gamification elements was based on Werbach and Hunter [51] who identified 15 important gamification components. According to Tolks and colleagues [27], the gamification elements that were used in the present study mainly focus on eliciting feelings of competence (task difficulty, task and speed reward, progress, and positive feedback) and autonomy (customizable profile, task difficulty, long-term objective). Elements that aim to fulfil social needs, such as teams, leaderboards and social network, were not considered due to constraints in the experimental setting. However, social game mechanics, such as communication, collaboration, cooperation, and competition, were tested in a follow-up study [52].

The pragmatic functionality of the non-gamified PC-Trainer was identical to the functions of the gamified version. This version also allowed for exploring and learning functionalities in a sandbox-like 
environment, and to make use of the help function. The only difference was that the above-mentioned gamification elements were excluded (see Figure 3).
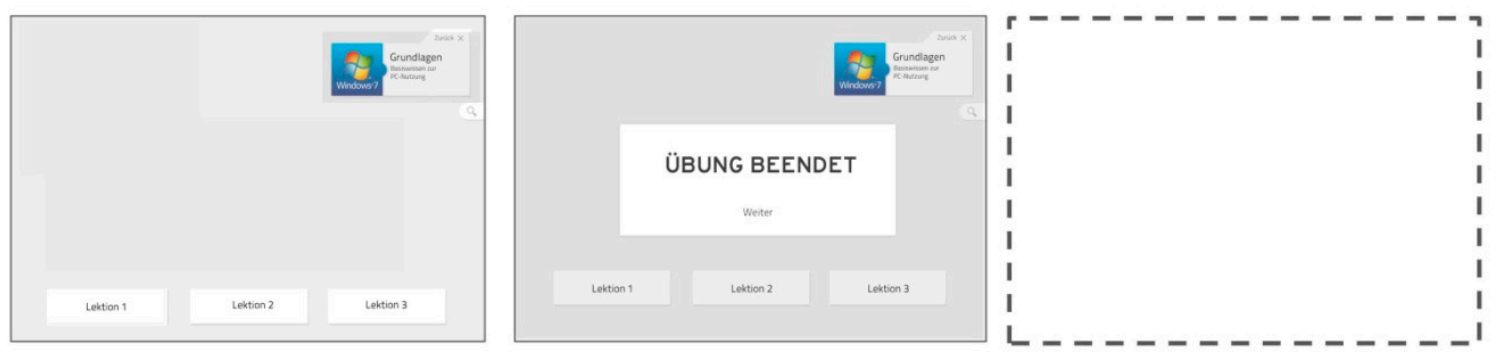

Figure 3. Screenshots of the non-gamified version of the PC trainer. Screenshots are showing the task selection window (left) and the feedback pop-up after solving a set of five tasks (middle), displaying "end of exercise". In this version, no personal profile existed.

The prototypes were tested in a laboratory and presented on a 19-inch monitor with a display resolution of $1280 * 1024 \mathrm{px}$. The computer was equipped with a standard mouse, keyboard, a webcam as well as speakers. The instructor table was set up behind a partition wall and contained a second screen to observe the participants' interaction with the application.

\subsection{Experimental Design and Dependent Variables}

The experimental design of the user test was a two-by-two between-subjects design with the two-level factor degree of gamification (gamified or non-gamified PC-Trainer) and the two-level factor age group (age group 60-69; and age group 70-79). The following dependent variables were measured:

(Shift of) Attitude. In order to learn about the general opinion towards (gamified) learning applications and to test changes of these attitudes after interaction with PC trainer, participants were asked seven five-point Likert scaled single-items before and after interacting with the applications. Items covered aspects of motivation (e.g., "My motivation in the long run is higher in case of game-based learning applications"), emotion (e.g., "Game-based learning applications can reduce the fear of solving novel tasks"), performance outcomes (e.g., "I believe the learning outcome of a game-based learning application to be high"), and acceptance (e.g., "I like the idea of teaching myself the handling of a new technology by playing a game"). This data was analyzed by a two-by-two mixed design with a two-level within-subjects factor time of measurement (before and after interaction with PC-Trainer) and the two-level between-subjects factor age group.

User Experience. User Experience ratings were collected by the meCUE (modular evaluation of key Components of User Experience) questionnaire [53] at the end of the experiment. MeCUE is a multidimensional tool measuring the perception of different product qualities (i.e., usefulness, usability, and visual aesthetics), positive and negative user emotions, and consequences of use (i.e., intention to use, and loyalty).

Use of Help Function. Furthermore, it was measured how often users pressed the help button during interaction to follow a step-by-step instruction.

Time on Task. The time to solve a set of five tasks was taken.

Mental Effort. After having worked on each task, participants answered the SEA scale (Subjektiv Erlebte Anstrengung) [54], a German equivalent to the RSME (ㅈating Scale Mental Effort by Zijlstra and van Doorn [55]). SEA is a single-item questionnaire that uses a scale ranging between 0 and 220 to express how demanding a task was $(0=$ not demanding; $40=$ little demanding; $120=$ quiet demanding; $190=$ very much demanding; $>200=$ extraordinary demanding).

Wish for Gamification. To measure a global preferences for one of the two versions of PC trainer, participants rated their preference on a seven-point Likert scale ranging from "strongly preferring the gamified version" $(-3)$ over "not preferring one over the other" $(0)$ to "strongly preferring the 
non-gamified version" (+3). Furthermore, subjects were asked to indicate for each element if they would implement it in their ideal learning application ("yes" or "no").

\subsection{Procedure}

Upon arrival, participants were seated at a computer workstation and informed about the agenda. They were fully informed of the purpose of the study and gave informed consent for their participation. Participants were free to withdraw their consent at any time of the study. No personal data was collected. First, participants filled out the technology commitment questionnaire by Neyer et al. [50] and specific single-item questions on the attitude towards games and game-based learning. Afterwards, participants were randomly assigned to work either with the gamified version or with the non-gamified version. Each person was asked to complete 15 tasks from two different domains (i.e., file management and Skype) with increasing difficulty. Tasks were presented in a fixed order. After the completion of a set of five tasks, participants had to rate the perceived workload for each task using the SEA scale [54]. During interaction, total task times for each task and the information whether the help function was used were logged. After solving all tasks, participants filled out the meCUE questionnaire [53] measuring the perception of product qualities, user emotions and intention to use. After the main experimental run, each group shortly interacted with the respective other version to get an impression of the look and feel of this version of the learning application. Therefore, one of the previous task sets was repeated. Due to the significantly shorter interaction phase the second part of the user test was not considered as a within-subjects factor. The interaction was necessary for the participants to answer the subsequent questions regarding gamified or non-gamified preferences, and to learn which gamification elements all participants would like to see implemented in their ideal learning application. Furthermore, the single items on attitude towards games and game-based learning were presented a second time. After answering a socio-demographic questionnaire, the experimental session ended, and participants received a compensation of $€ 12$ each. Each test session lasted about one hour.

\subsection{Assumptions}

(Shift of) Attitude. We were interested whether older adults have an open mind about gamified learning applications that are PC-based and whether game-based learning could support their interaction with technology, reduce perceived barriers and risks, and improve long-term motivation. In case the attitude towards game-based ICT learning would be low, we assumed that after the participants interacted with the learning application (which was designed to be easy to use, and avoid frustration and mental overload), their attitude towards learning games will be more positive than in the beginning. In particular, it was expected that, after having worked with the software, long-term motivation, learning outcomes, and general acceptance of game-based learning applications will be rated higher, while negative feelings towards unknown technologies (i.e., fear of solving novel tasks) will be generally reduced. No differences between the age groups or the degree of gamification were expected.

Wish for Gamification. Whether older adults preferred the gamified or the non-gamified version and which gamification elements were liked or disliked, served as exploratory research questions. Based on findings of interviews and focus groups conducted in advance [42,49], we tried to implement rather mild and meaningful gamification elements that are widely accepted within the user group and have the highest potential for a positive impact.

User Experience. As game mechanics are associated with the elicitation of emotional experiences [1], personal growth [21,56] and wellbeing [27], we expected the gamified version to receive superior user experience ratings. Specifically, we assumed that the gamified version would elicit higher positive emotions and reduce negative emotions. Following Hunicke and colleagues [57] who argued for a close relationship between game mechanics, dynamics, and aesthetics, we expected higher ratings of hedonic product perceptions for the gamified version, including visual aesthetics. No differences were expected with regard to the perception of pragmatic product qualities, i.e., usability ratings. We did 
not expect to find an effect of age group or an interaction of age group and degree of gamification on user experience ratings.

Use of Help Function. Since the use of gamification elements was supposed to motivate autonomous exploration of the system, the help button was expected to be clicked less often than in the gamified version. It was expected that the older age group (70 to 79 years) would access the help function more often than the younger age group (60 to 69 years), since they are often less experienced with technology and need more guidance. We did not expect to find an interaction between the age groups and the degree of gamification.

Time on Task. We did not expect a difference of total task time for degree of gamification. However, we assumed that the younger age group (60 up to 69 years) is more familiar with computer related tasks than the older age group (70 up to 79 years) and thus will solve the tasks quicker. In case time on task greatly diverges between the age groups, this certainly needs to be considered in future designs for older adults. We did not expect to find an interaction between the age groups and the degree of gamification.

Mental Effort. Gamified systems may subjectively appear to be more playful and less effortful, but since the perception and interpretation of gamification elements requires slightly more attentional resources from the user, we did not expect a difference in perceived mental effort between the two PC-Trainer versions. With respect to the factor age group, we assumed that the younger seniors report less mental effort to solve the tasks than the older seniors. No interaction between the age groups and the degree of gamification was assumed.

With the assumption of an effect of $f=0.45$ in a univariate design, a total sample size of 44 participants is required to reach a power of $1-\beta=0.90$ (g-power). Hence, a sample size of forty-eight participants can be regarded as adequate.

\section{Results}

To ensure the fulfilment of the statistical analyses, the distribution of all dependent variables and the homogeneity of error variances were examined. To test the assumption of normal distribution, the Shapiro-Wilk test was used, which is particularly sensitive for small sample sizes. The $p$-values are between 0.01 and 0.3 . According to Hair [58], data is considered normally distributed if skewness is between -2 and +2 and kurtosis is between -7 and +7 . This requirement is met by all dependent variables. Regarding the homogeneity of error variances (Levene test), no $p$-values lower than 0.05 occurred.

(Shift of) Attitude. When looking at the descriptive statistics and the general level of the single-item ratings, it can be seen that all positive items measuring motivation, reduction of perceived risk, learning outcome, and the acceptance of game-based learning applications are strongly agreed upon (see Table 1). Only the two inverted items "1. I prefer to read manuals first and then to try out a new technology" and " 2 . In case I have to use a computer for a game-based learning application, I do not want to spend much time with it" are agreed upon only slightly or partly. Means and standard deviations of all dependent variables are summarized in Table 1.

In order to analyze differences that are affected by age group and time of measurement, a two-by-two multivariate analysis of variance (MANOVA) was calculated. With respect to the factor age group, significant main effects for the two single-items \#3 and \#5 were obtained. Seniors of the older age group perceived a greater reduction of fear when solving novel tasks by the use of game-based learning applications than the younger ones $\left(F(1,46)=4.144, p=0.048^{*}, \eta_{\text {part }}{ }^{2}=0.083\right)$. In addition, older seniors felt generally more encouraged to deal with new technologies after interacting with PC-Trainer than younger seniors $\operatorname{did}\left(F(1,46)=5.466, p=0.024^{*}, \eta_{\text {part }}{ }^{2}=0.106\right)$. 
Table 1. Mean ratings and standard deviations of single items measuring participants' attitude towards interactive learning applications. The response format was a five-point Likert-scale ( 1 = "disagree", 2 = "slightly agree", 3 = "partly agree", 4 = "strongly agree" 5 = "absolutely agree").

\begin{tabular}{|c|c|c|c|c|}
\hline \multirow{2}{*}{ Item } & \multicolumn{2}{|c|}{ Age Group 60-69 } & \multicolumn{2}{|c|}{ Age Group 70-79 } \\
\hline & Pre $M(S D)$ & Post $M(S D)$ & Pre $M(S D)$ & Post $M(S D)$ \\
\hline $\begin{array}{l}\text { 1. I prefer to read manuals first and then to try } \\
\text { out a new technology. }\end{array}$ & $2.83(1.07)$ & $2.30(0.97)$ & $2.92(1.29)$ & $2.36(1.08)$ \\
\hline $\begin{array}{l}\text { 2. In case I have to use a computer for a } \\
\text { game-based learning application, I do not want } \\
\text { to spend much time with it. }\end{array}$ & $2.39(1.08)$ & $2.04(1.30)$ & $2.28(1.06)$ & $1.96(0.98)$ \\
\hline $\begin{array}{l}\text { 3. Game-based learning applications can reduce } \\
\text { the fear of solving novel tasks. }\end{array}$ & $3.22(1.17)$ & $3.52(1.31)$ & $3.76(1.09)$ & $4.12(0.97)$ \\
\hline $\begin{array}{l}\text { 4. I believe the learning outcome of a } \\
\text { game-based learning application to be high. }\end{array}$ & $3.52(0.85)$ & $3.43(1.20)$ & $3.72(0.98)$ & $4.12(0.97)$ \\
\hline $\begin{array}{l}5 . \text { I believe that a game could help me to deal } \\
\text { with technology. }\end{array}$ & $3.22(1.00)$ & $3.39(1.20)$ & $3.88(0.93)$ & $3.96(1.21)$ \\
\hline $\begin{array}{l}\text { 6. My motivation in the long run is higher in case } \\
\text { of game-based learning applications. }\end{array}$ & $3.48(1.04)$ & $3.22(1.28)$ & $3.36(1.15)$ & $3.88(0.93)$ \\
\hline $\begin{array}{l}\text { 7. I like the idea of teaching myself the handling } \\
\text { of a new technology by playing a game. }\end{array}$ & $3.87(1.01)$ & $3.83(1.30)$ & $4.12(1.05)$ & $4.36(0.95)$ \\
\hline
\end{tabular}

Furthermore, the analysis revealed significant main effects of time of measurement for the two single-items \#1 and \#2, and a tendency for the single-item \#3. First, participants' preference for reading manuals before trying out a new technical system decreased significantly after the experiment $(F(1,46)$ $\left.=13.462, p=0.001^{* * *}, \eta_{\text {part }}{ }^{2}=0.226\right)$. Secondly, participants became significantly more willing to spend time on learning applications that are computer-based $\left(F(1,46)=5.051, p=0.029 *, \eta_{\text {part }}{ }^{2}=0.099\right)$. Finally, after the experiment, seniors showed the tendency to stronger agree that game-based learning applications may reduce the fear of solving novel tasks $\left(F(1,46)=3.763, p=0.059, \eta_{\text {part }}{ }^{2}=0.076\right)$.

Finally, the analysis revealed a significant interaction of age group and time of measurement for item \#6 $\left(F(1,46)=4.623, p=0.037^{*}, \eta_{\text {part }}{ }^{2}=0.091\right)$. Indicating that the attitude, that motivation in the long run is higher in case of applications that use game elements, improved more in the older age group than in the younger age group.

Wish for Gamification. After working with both applications, all users were asked about their personal preference using a seven-point semantic differential. Answers greatly varied from "strongly preferring the non-gamified version (-3)" over "not preferring one over the other (0)" to "strongly preferring the gamified version $(+3)$ ". Twenty-two participants favored the non-gamified application $(\leq-1), 10$ being undecided $(0)$ and 16 preferring the gamified version $(\geq 1)$. Preferring the gamified version was significantly correlated with the individual affinity towards games in general (as measured with a single item); $r=0.307, p=0.034^{*}$. Interestingly, the younger age group showed to have a higher preference for the non-gamified version $(M=-0.57, S D=1.973)$ than the older age group $(M=0.08, S D=2.197)$, and the gamified version was slightly more preferred by users with a low score in technology commitment $(M=0.07, S D=2.303)$, while users with a medium or a low score rather preferred the learning application without gamification elements $(M=-0.33 ; S D=1.78$ and $M=-0.38$; $S D=2.160)$. However, all these differences were non-significant.

The liking of specific gamification elements was measured in the end of the experiment. All forty-eight participants were asked to state for each gamification element whether they would integrate it as a feature in their own individually adjustable learning software or not. Most of the participants preferred progress visualization $(n=44)$ and the option to choose between tasks of a specified difficulty $(n=40)$. In addition, the long-term objective $(n=36)$ and positive feedback after the successful solution of a task set $(n=33)$ were rather preferred. Speed reward $(n=30)$, reward for solving tasks $(n=29)$, and the personal profile $(n=25)$ were less accepted.

To examine whether specific gamification elements appealed to different types of participants, possible relationships between desire for an element and game affinity as well as system preference 
were analyzed. No significant association between general game affinity and a desire for any of the gamification elements could be found. However, significant relations were found between desire for some of the elements and system preference (Figure 4. Participants who preferred the gamified over the non-gamified version were significantly more likely to desire an immediate reward for solving a task (Fisher's $X^{2}(1,48)=15.342, p<0.01 * *$, Cramer's $V=0.565$ ) as well as getting positive feedback after a set of tasks (Fisher's $X^{2}(1,48)=8.262, p=0.016^{*}$,Cramer's $\left.V=0.415\right)$. For the element "long-term objective", the difference showed a tendency to be significant (Fisher's $X^{2}(1,48)=4.897, p=0.081$, Cramer's $V=0.339$ ).

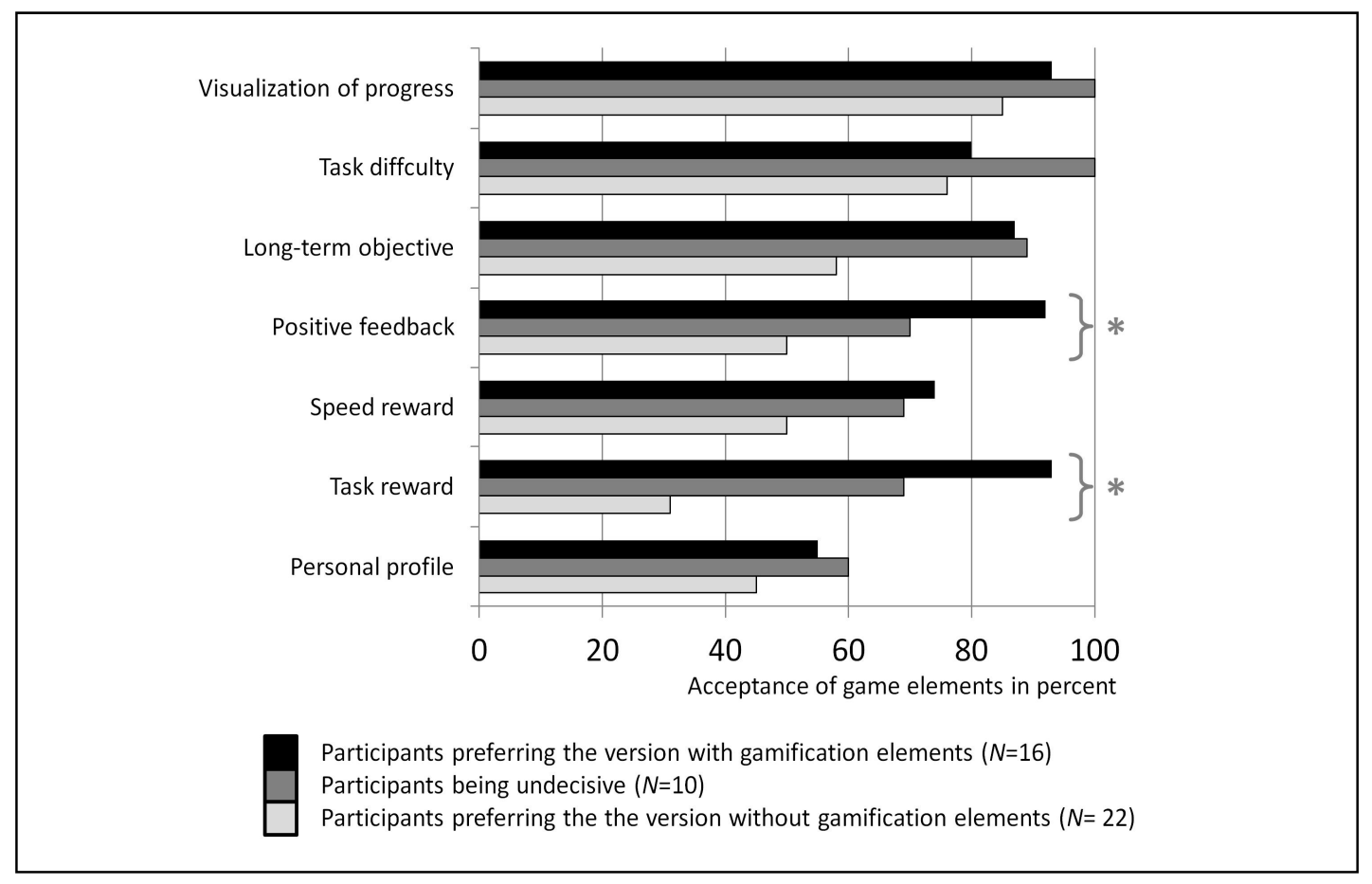

Figure 4. Acceptance of specific gamification elements by system preference. Significance level: * $p<0.05$.

User Experience. The user experience ratings were very positive for both PC-Trainer versions (see Figure 5). The two-by-two MANOVA with the between subjects factors degree of gamification and age group revealed a significant main effect of degree of gamification only for visual aesthetics $\left(F(1,44)=4.624 ; p=0.037^{*} ; \eta_{\text {part }}{ }^{2}=0.095\right)$, indicating that higher ratings were reported in case of the gamified version. No other significant main effects of degree of gamification and age group were found. Furthermore, all interactions were non-significant.

Use of Help Function. With respect to the help function, we predicted less usage in the gamified PC-Trainer, since autonomous task completion was rewarded. To solve 15 tasks with the gamified version, the help button was pressed 5.57 times on average $(S D=3.63)$. This is slightly, but not statistically, less than in the non-gamified application $(M=5.91, S D=4.34) ;(F(1,42)=3.960 ; p=0.053$ $\left.\eta_{\text {part }}{ }^{2}=0.086\right)$. Overall, it became obvious that one third of the generally rather simple tasks needed additional help and assistance.

Time on Task. No main effect of degree of gamification was found, but a main effect of age group $\left(F(1,44)=9.703 ; p=0.003 * ; \eta_{\text {part }}{ }^{2}=0.181\right)$, indicating that younger seniors solved each set of five tasks quicker than older seniors $(M=384.7 \mathrm{sec}, S D=136.53 \mathrm{vs} . M=761.48 \mathrm{sec}, S D=561.59)$.

Mental effort. No main and interaction effects of degree of gamification and age group were found. The tendency that younger seniors reported that the tasks were not or only little demanding $(M=25.41, S D=15.12)$, whereas older seniors rated the tasks on average as quiet demanding 
$(M=101.08, S D=183.59)$. However, this tendency failed to reach significance $(F(1,44)=3.697$; $\left.p=0.061 ; \eta_{\text {part }}{ }^{2}=0.078\right)$.

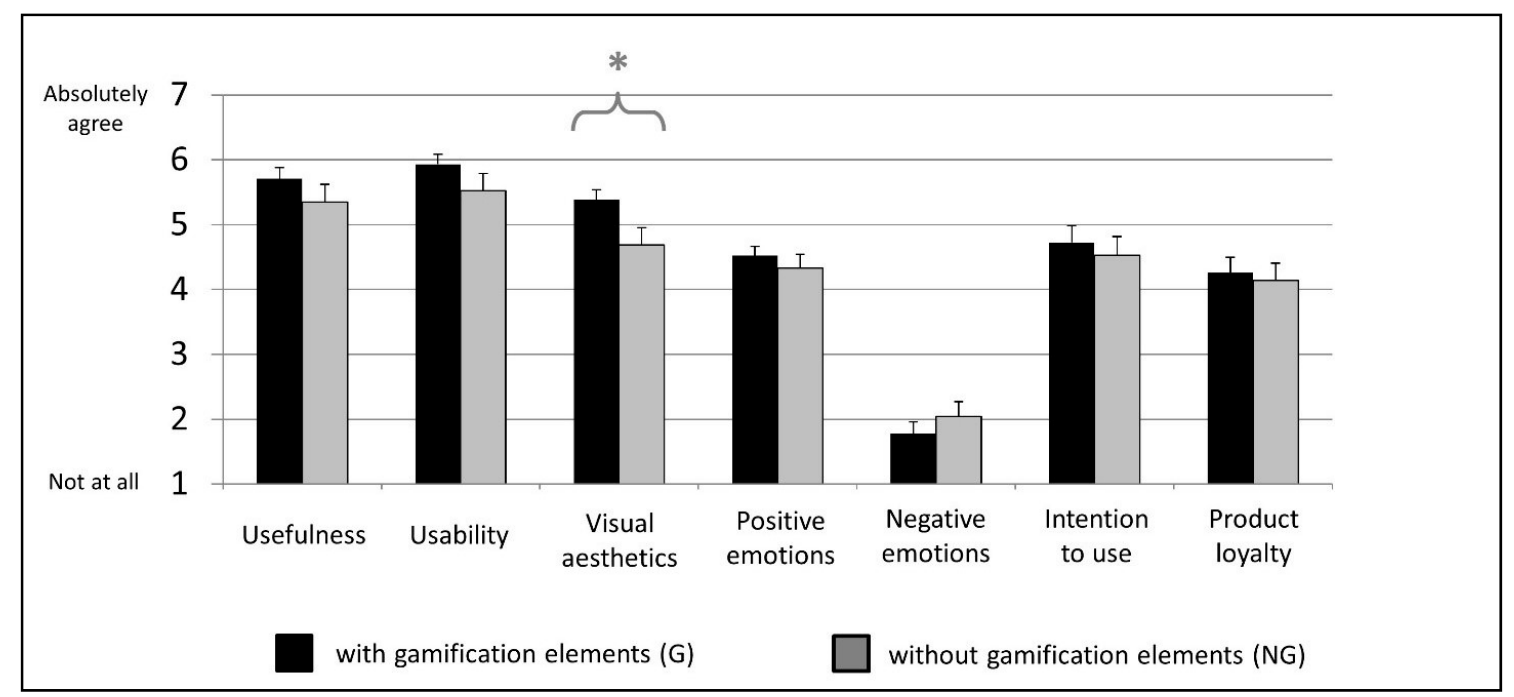

Figure 5. Mean user experience ratings (meCUE questionnaire) for the gamified and the non-gamified version. Error bars indicate the standard error of the mean. Significance level: ${ }^{*} p<0.05$ resulting from the two-by-two multivariate analyses of variance (MANOVA).

\section{Discussion}

(Shift of) Attitude. The ratings of the single-items measuring motivation and expectations of learning outcomes and acceptance show that both, the younger and the older seniors, are generally very open-minded towards the concept of game-based learning applications. We found some evidence, that especially older seniors (70 up to 79 years) report more self-confidence and positive expectations towards game-based learning applications than the younger seniors (60 up to 69 years). With respect to attitude changes that occurred over the course of the experiment, results show that actively experiencing the prototypical learning application significantly influences judgments and expectations. After the experiment participants indicated to be willing to spend more time at the computer for learning and were less likely to prefer conventional help methods like manuals. The interaction with one of the two systems seems to have strengthened self-confidence and to have improved ratings of attractiveness. Again, we found evidence that this effect of attitude changes before and after interacting with a prototype can be observed especially for older seniors. Furthermore, these changes nicely demonstrate that in early user testing, users must have the possibility of actively explore and interact with a design solution in order to make valid judgments about the product. However, it remains unclear if those attitude changes are long lasting, particularly when participants encounter new frustrating experiences with unknown technical products.

User Experience. The comparison of the two levels of gamification with respect to user experience ratings, found that visual aesthetics are higher in case of the gamified version than for the learning application without gamification elements. The elements used in the present study seem to be visually appealing and stimulating. This result in line with the Mechanics-Dynamics-Aesthetics- (MDA-)model by Hunicke et al. [57], which suggests a strong relationship between game mechanics, dynamics, and aesthetics. According to this model, game elements are directly eligible for eliciting audiovisual sensation. Regarding user emotions no significant differences between both versions was found, neither for positive nor for negative emotions. The very similar results of positive and negative emotions might be affected by the laboratory setting, as it is always a challenge to evoke personal significance [59]. In the present study, visual sensation alone seemed to be not enough to provoke a more positive emotional experience than a user-centered learning application without gamification 
already does. In addition, no significant differences can be found between the ratings of instrumental product qualities, indicating that ratings of usability and usefulness reach a comparable level for both versions. Descriptive statistics indicate that, in our study, usability and usefulness are rated considerably above average. This finding suggests that the gamified and the non-gamified learning application are perceived as highly pragmatic, supportive and goal oriented. It can be supposed that the basic functionality of the prototype including the presentation of practical problems and the use of step-by-step-instructions seems to be of high value for seniors. Therefore, our results support the assumption, that for the intended target group additional effects of the use of gamification elements become negligibly small, if the fundamental product concern of usefulness is fulfilled.

Use of Help Function. When analyzing the use of the help function, we did not find evidence for the assumption that the use of gamification elements supports the autonomous exploration of the system. In the gamified version, the help button was pressed less often than in the non-gamified version, however, this result is non-significant. Surprisingly, even for tasks with an expected low level of difficulty, participants activated the help function quite often, when interacting with both, the gamified and the non-gamified learning application. It seems that an interactive step-by-step task instruction written in easy language is perceived as useful and attractive by older users.

Time on Task. The use of gamification elements did not affect time on task. However, we found support for the assumption that younger seniors solve the tasks quicker than older seniors. Designers should consider warranting more time to older adults with increasing age to avoid frustration.

Mental Effort. Although the gamified version is more complex, mental effort was not rated higher than in the non-gamified version. The tendency was found, that reported mental effort is higher in the older age group of seniors, which is in line with the increased time on task found in this group.

Wish for Gamification. Preferences for one of the two systems are almost equally distributed. Roughly one third reported to generally prefer the gamified learning application, one third to prefer the non-gamified version, and the last third cannot decide. Seniors who like playing games are more likely to prefer the gamified version of the learning application. In relation to further sociodemographic characteristics, no significant differences can be reported with respect to the preference ratings. Descriptive statistics show that the gamified version of the learning application is especially preferred by older seniors (70 up to 79 years) and by users who reported a lower commitment to new technologies. This pattern, however, corresponds with the data that were collected by the single items measuring the shift of attitude. Here we found evidence that older seniors perceived a greater reduction of fear and felt generally more encouraged to deal with new problems. Taking these findings together, it can be assumed that game-inspired design might be of promising help to overcome perceived motivational barriers when learning how to use ICT, especially if users have less prior knowledge and expertise with new technologies.

But which specific gamification elements should designers implement for older seniors and which should be avoided?. We identified gamification elements with generally high preference ratings that can be implemented for all older seniors without doubt. Among these are visualization of progress and distinguished levels of task difficulty. It can be concluded that these rather pragmatic-oriented gamification elements are perceived as supportive by a majority of senior users and that this preference is independent from sociodemographic variables, such as age, gender, educational level, preference for games, and prior experience. The gamification element long-term objective (completing a puzzle and receiving a surprise) was also rather well-accepted and selected for the individual learning application by two out of three participants. We further identified gamification elements that are generally less accepted such as speed reward and a customizable personal profile. These elements should only be implemented with caution or rather be left out. It might be that speed reward is more promising when users have preliminary knowledge on how to solve a task and the goal is to consolidate the operative execution. As the frequent utilization of the help function suggests, most participants in the present study were rather unexperienced ICT users. The remaining gamification elements, which are rewards for solving single tasks and continuous positive feedback on smaller task sets, were selected 
into the ideal individual learning application by at least every second participant. Obviously not all participants felt the need for being continuously endorsed when learning novel ICT task. Interestingly, we found that especially those seniors that clearly favored the gamified version were particularly fond of continuous positive feedback and receiving rewards for each task they have accomplished. They seemed to need the feedback as guidance to know they are on the right track. Whereas the remaining seniors rather disliked the intensive endorsement through these two features and decided against the gamified version, albeit they liked many of the other game features. The disliking of these two features seemed to be of an intensity that caused the complete rejection of the gamified version in this second group. When designing a gamified learning application for older adults, these two gamification elements should therefore be implemented as an option which is either selected in or out by each user in order to address the needs of all senior users.

As we further found that the preference for a high degree of gamification and the personal liking of games in general are associated with another, it could be also an option to provide high gamification intensity only to those people that like games. Those who do not enjoy playing games in general could be offered an application that integrates only the basic features that were liked by all seniors (visualization of progress, levels of task difficulty). Here the remaining features could be implemented by choice, in case these older seniors want to test or even integrate them later on. This would be a very efficient approach in order to customize game-based systems and to support the motivation of senior users in a highly individual way.

\section{Conclusions}

The presented work demonstrates that senior users are very open-minded about game-inspired design and that, in general, older adults adopt a positive attitude towards gamification elements embedded in useful applications. As our results indicate, this is not only the case for products and services in Health-IT, but can be transferred to other domains, such as learning how to use common information and communication technology (ICT). However, a differentiated picture must be drawn when the focus is on the acceptance of specific gamification elements. Here, we found some features to be generally high in acceptance (e.g., visualization of progress and offering diverse levels of task difficulty), and generally low in acceptance (e.g., speed reward and a customizable personal profile). Continuous gamification elements such as positive feedback and receiving rewards for each task accomplished, were rated quite diverse. Whereas some senior users enjoyed these features a lot, the complete opposite was true for others. To solve this conflict, a customizable approach of gamification could be fruitful, where game mechanics are integrated in a system as optional features and activated (or de-activated) by the user according to individual preferences. This approach would allow for giving access to users who highly differ in prior experience and for engaging people by considering their personal preferences and requirements.

Our findings underline the importance of developing a profound understanding of users and the tasks they want to accomplish in order to find appropriate design solutions. We believe that following a user-centered design (UCD) process is of crucial importance when developing for older users, since attitudes, needs, requirements, and prior experience substantially differ from those who design and develop such systems.

Author Contributions: Conceptualization, D.H.C. and M.M.; methodology, M.M. and D.H.C.; formal analysis, M.M.; investigation, D.H.C. and M.M.; writing—original draft preparation, D.H.C. and M.M.; writing-review and editing, D.H.C. and M.M.; visualization, M.M. All authors have read and agreed to the published version of the manuscript.

Funding: This research was funded by the German Ministry of Research and Education (BMBF) as part of project "GaTE: Gamification of Technology for the Elderly" (\# 16SV6183).

Acknowledgments: We thank Franziska Adler, Juliane Bürglen, Sophie Neef and Josephine Grauert for their help in conducting the interviews and the user study as well as Matthias Löwe for implementing both versions of the interactive learning application. 
Conflicts of Interest: The authors declare no conflicts of interest.

\section{References}

1. Jordan, P.W. Designing Pleasurable Products: An Introduction to the New Human Factors; Taylor \& Francis: Abingdon, UK, 2001.

2. Pohlmeyer, A.E. Design for happiness 2012. Interfaces 2012, 92, 8-11.

3. Desmet, P.; Hassenzahl, M. Towards happiness: Possibility-driven design. Hum. Comput. Interact. Agency Perspect. 2012, 3-27. [CrossRef]

4. Kamp, I.; Desmet, P. Measuring Product Happiness. In Proceedings of the International Conference on Human-Computer Interaction (CHI) 2014-Extended Abstracts, Toronto, QC, Canada, 26 April-1 May 2014; ACM Press: New York, NY, USA, 2014; pp. 2509-2514. [CrossRef]

5. Hamari, J.; Koivisto, J.; Sarsa, H. Does Gamification Work?.-A Literature Review of Empirical Studies on Gamification. In Proceedings of the 47th Hawaii International Conference on System Sciences, Waikoloa, HI, USA, 6-9 January 2014; pp. 3025-3034.

6. Stampfl, N. Die Verspielte Gesellschaft; Heise Verlag: Hannover, Germany, 2012.

7. Domínguez, A.; Saenz-De-Navarrete, J.; De-Marcos, L.; Fernández-Sanz, L.; Pagés, C.; Martínez-Herraíz, J.J. Gamifying learning experiences: Practical implications and outcomes. Comput. Educ. 2013, 63, 380-392. [CrossRef]

8. Landers, R.N.; Callan, R.C. Casual social games as serious games: The psychology of gamification in undergraduate education and employee training. In Serious Games and Edutainment Applications; Springer: London, UK, 2011; pp. 399-423.

9. Su, C.H.; Cheng, C.H. A mobile gamification learning system for improving the learning motivation and achievements. J. Comput. Assist. Learn. 2015, 31, 268-286. [CrossRef]

10. Makanawala, P.; Godara, J.; Goldwasser, E.; Le, H. Applying gamification in customer service application to improve agents' efficiency and satisfaction. In International Conference of Design, User Experience, and Usability; Springer: Berlin, Germany, 2013; pp. 548-557.

11. Rauch, M. Best practices for using enterprise gamification to engage employees and customers. In International Conference on Human-Computer Interaction; Springer: Berlin/Heidelberg, Germany, 2013; pp. 276-283.

12. Uskov, A.; Sekar, B. Serious games, gamification and game engines to support framework activities in engineering: Case studies, analysis, classifications and outcomes. In Proceedings of the IEEE International Conference on Electro/Information Technology, Milwaukee, WI, USA, 5-7 June 2014; pp. 618-623.

13. Bista, S.K.; Nepal, S.; Paris, C.; Colineau, N. Gamification for online communities: A case study for delivering government services. Int. J. Coop. Inf. Syst. 2014, 23, 1441002. [CrossRef]

14. Seufert, M.; Lorey, K.; Hirth, M.; Hoßfeld, T. Gamification framework for personalized surveys on relationships in online social networks. In Proceedings of the 2013 IEEE/ACM 6th International Conference on Utility and Cloud Computing, Dresden, Germany, 9-12 December 2013; pp. 482-487.

15. Pereira, P.; Duarte, E.; Rebelo, F.; Noriega, P. A review of gamification for health-related contexts. In International Conference of Design, User Experience, and Usability; Springer: Cham, Switzerland, 2014.

16. de Vette, F.; Tabak, M.; Dekker-van Weering, M.; Vollenbroek-Hutten, M. Engaging elderly people in telemedicine through gamification. JMIR Serious Games 2015, 3, e9. [CrossRef]

17. Dannehl, S.; Seiboth, D.; Doria, L.; Minge, M.; Lorenz, K.; Thüring, M.; Kraft, M. A smartphone-based system to improve adherence in scoliosis therap. I Com J. Interact. Media 2016, 15, 313-319.

18. Minge, M.; Ivanova, E.; Lorenz, K.; Thüring, M.; Krüger, J.; Joost, G. BeMobil: Developing a User-Friendly and Motivating Telesystem for Motor Rehabilitation after Stroke. In Proceedings of the International Conference on Rehabilitation Robotics, ICORR 2017, London, UK, 17-20 July 2017; pp. 870-875.

19. Darejeh, A.; Salim, S.S. Gamification Solutions to Enhance Software User Engagement-A systematic Review. Int. J. Hum. Comput. Interact. 2016. [CrossRef]

20. Gentry, S.V.; Gauthier, A.; Ehrstrom, B.L.E.; Wortley, D.; Lilienthal, A.; Car, L.T.; Car, J. Serious gaming and gamification education in health professions: Systematic review. J. Med Internet Res. 2019, 21, e12994. [CrossRef]

21. Deterding, S. The Lens of Intrisic Skill Atoms: A Method for Gameful Design. Hum. Comput. Interact. 2015, 30, 294-335. [CrossRef] 
22. Zichermann, G.; Cunningham, C. Gamification by Design; O'Reilly: Sebastopol, CA, USA, 2011.

23. Kapp, K.M. The Gamification of Learning and Instruction: Game-Based Methods and Strategies for Training and Education; John Wiley \& Sons: Hoboken, NJ, USA, 2012.

24. Ryan, R.M.; Rygby, C.S.; Przybilski, A.K. The motivational pull of video-games: A self-determination approach. Motiv. Emot. 2005, 30, 347-364. [CrossRef]

25. Sheldon, K.M.; Filak, V. Manipulating autonomy, competence, and relatedness support in a game-learning context: New evidence that all three needs matter. Br. J. Soc. Psychol. 2008, 47, 267-283. [CrossRef] [PubMed]

26. Ryan, R.M.; Deci, E.L. Self-determination theory and the facilitation of intrinsic motivation, social development, and well-being. Am. Psychol. 2000, 55, 68-78. [CrossRef] [PubMed]

27. Tolks, D.; Sailer, M.; Dadaczynski, K.; Lampert, C.; Huberty, J.; Paulus, P.; Horstmann, D. ONYA-The Wellbeing Game: How to Use Gamification to Promote Wellbeing. Information 2019, 10, 58. [CrossRef]

28. Sailer, M.; Hense, J.U.; Mayr, S.K.; Mandl, H. How gamification motivates-An experimental study of the effects of specific game design elements on psychological need satisfaction. Comput. Hum. Behav. 2017, 69, 371-380. [CrossRef]

29. Pedro, L.Z.; Lopes, A.M.Z.; Prates, B.G.; Vassileva, J.; Isotani, S. Does gamification work for boys and girls? An exploratory study with a virtual learning environment. In Proceedings of the ACM Symposium on Applied Computing, Salamanca, Spain, 13 April 2015; pp. 214-219.

30. Frost, R.D.; Matta, V.; MacIvor, E. Assessing the efficacy of incorporating game dynamics in a learning management system. J. Inf. Syst. Educ. 2015, 26, 59-70.

31. Sailer, M.; Homner, L. The Gamification of Learning: A Meta-analysis. Educ. Psychol. Rev. 2020, 32, 77-112. [CrossRef]

32. Schmidt, M.; Fisher, A.P.; Sensenbaugh, J. User Experience (re)Design and Evaluation of a Self-Guided, Mobile Health App for Adolescents with Mild Traumatic Brain Injury. J. Form. Des. Learn 2020. [CrossRef]

33. Ruffino, P. From engagement to life, or: How to do things with gamification? In Rethinking Gamification; Meson Press: Lüneburg, Germany, 2014; pp. 47-69.

34. Deterding, S. Eudaimonic Design, or: Six Invitations to Rethink Gamification. In Rethinking Gamification; Fuchs, M., Fitzek, S., Ruffino, P., Schrape, N., Eds.; Meson Press: Lüneburg, Germany, 2014; pp. 305-323.

35. Robertson, M.D. Can't Play, Won't Play. In Hide \& Seek - Inventing New Kinds of Play. 6 October 2010. Available online: http://hideandseek.net/2010/10/06/cant-play-wont-play/ (accessed on 17 January 2016).

36. Raczkowski, F. Making Points the Point: Towards a History of Ideas of Gamification 2014. In Rethinking Gamification; Fuchs, M., Fizek, S., Ruffino, P., Eds.; Meson Press: Lüneburg, Germany, 2014; pp. 141-160.

37. Nicholson, S. A recipe for meaningful gamification. In Gamification in Education and Business; Springer: Cham, Switzerland, 2015; pp. 1-20.

38. Broer, J. Gamification and the Trough of Disillusionment. In Mensch E Computer 2014-Workshopband; Butz, A., Koch, M., Schlichter, J., Eds.; De Gruyter Oldenbourg: Berlin, Germany, 2014; pp. 389-395.

39. Mekler, E.D.; Brühlman, F.; Tuch, A.N.; Opwis, K. Towards Understanding the Effects of Individual Gamification Elements on Intrinsic Motivation and Performance. Comput. Hum. Behav. 2017, 71, 525-534. [CrossRef]

40. Gartner Gartner Says by 2014, 80 Percent of Current Gamified Applications Will Fail to Meet Business Objectives Primarily Due to Poor Design 2012. Available online: http://www.gartner.com/newsroom/id/ 2251015 (accessed on 17 August 2017).

41. Fogel, G. Will 80\% of Gamification Projects Fail? Giving Credit to Gartner's 2012 Gamification Forecast 2015. Available online: http://www.gameffective.com/gamification-basics/will-80-of-gamification-projects-fail/ (accessed on 17 August 2017).

42. Cymek, D.H.; Bürglen, J.; Minge, M. Identifying the Potential to Motivate Older Adults' Use of Information and Communication Technology through Serious Games. In Proceedings of the 1st International Symposium on Simulation \& Serious Games 2014 (ISSSG 2014) at Serious Games Conference, Seoul, Korea, 23-24 May 2014; pp. 130-136.

43. Mitzner, T.L.; Boron, J.B.; Fausset, C.B.; Adams, A.E.; Charness, N.; Czaja, S.J.; Dikstra, K.; Fisk, A.D.; Rogers, W.A.; Sharit, J. Older adults talk technology: Technology usage and attitudes. Comput. Hum. Behav. 2010, 26, 1710-1721. [CrossRef]

44. Bellotti, F.; Kapralos, B.; Lee, K.; Moreno-Ger, P.; Berta, R. Assessment in and of serious games: An overview. Adv. Hum. Comput. Interact. 2013. [CrossRef] 
45. Gomez-Gurley, K.; McLaughlin, A.C.; Coleman, M.G.; Allaire, J.C. Accessibility in Serious Games for Adults Aging with Disability. In International Conference on Human Aspects of IT for the Aged Population; Springer: Cham, Switzerland, 2015; pp. 61-71.

46. Gerling, K.M.; Masuch, M. Exploring the Potential of Gamification Among Frail Elderly Persons 2011. In Proceedings of the CHI 2011 Workshop Gamification: Using Game Design Elements in Non-Game Contexts, Vancouver, BC, Canada, 7-12 October 2011.

47. Hauser, F.; Leich, A.; Schiffer, K. Facing the Challenge: Evaluation of Serious Games/Herausforderung Serious Games: Evaluation von Spielen mit Lerncharakter. I-COM 2013, 12, 32-38. [CrossRef]

48. Koivisto, J.; Hamari, J. Demographic differences in perceived benefits from gamification. Comput. Hum. Behav. 2014, 35, 179-188. [CrossRef]

49. Minge, M.; Bürglen, J.; Cymek, D.H. Exploring the Potential of Gameful Interaction Design of ICT for the Elderlyn. In HCI International 2014-Communications in Computer and Information Science. Posters' Extended Abstracts. Part II; Stephanidis, C., Ed.; Springer International Publishing: Berlin, Germany, 2014; pp. 304-309.

50. Neyer, F.J.; Felber, J.; Gebhardt, C. Entwicklung und Validierung einer Kurzskala zur Erfassung von Technikbereitschaft. Diagnostica 2012, 58, 87-99. [CrossRef]

51. Werbach, K.; Hunter, D. For the Win: How Game Thinking Can Revolutionize Your Business; Wharton Digital Press: Philadelphia, PA, USA, 2012.

52. Wagner, I.; Minge, M. The Gods play dice together: The influence of social elements of gamification on seniors' user experience. In HCI International 2015. Posters' Extended Abstracts, Part I; Stephanidis, C., Ed.; Springer International Publishing: Berlin, Germany, 2015; pp. 334-339.

53. Minge, M.; Riedel, L. meCUE—Ein modularer Fragebogen zur Erfassung des Nutzungserlebens. In Mensch und Computer; Boll, S., Maaß, S., Malaka, R., Eds.; Oldenbourg Verlag: München, Germany, 2013; p. 89998.

54. Eilers, K.; Nachreiner, F.; Hänecke, K. Entwicklung und Überprüfung einer Skala zur Erfassung subjektiv erlebter Anstrengung. Z. Für Arb. 1986, 40, 215-224.

55. Zijlstra, F.; van Doorn, L. The Construction of a Scale to Measure Subjective Effort; Technical Report; Delft University of Technology: Delft, The Netherlands, 1985.

56. Csikszentmihalyi, M. Flow: The Psychology of Optimal Experience; Harper and Row: New York, NY, USA, 1990.

57. Hunicke, R.; LeBlanc, M.; Zubek, R. MDA-A Formal Approach to Game Design and Game Research. In Proceedings of the Workshop on Challenges in Game Artificial Intelligence at the 19th National Conference on Artificial Intelligence, San José, CA, USA, 25-26 July 2004; pp. 1-14.

58. Hair, J.F.; Black, W.C.; Babin, B.J.; Anderson, R.E. Multivariate Data Analysis; Pearson Prentice Hall: New Jersey, 2010.

59. Wilhelm, F.H.; Grossman, P. Emotions beyond the laboratory: Theoretical fundaments, study design, and analytic strategies for advanced ambulatory assessment. Biol. Psychol. 2010, 84, 552-569. [CrossRef] 